\title{
The Art Opening: Proximity and Potentiality at Events
}

\section{Martin Fuller}

Technische Universität Berlin

\section{Julie Ren}

Humboldt-Universität zu Berlin

\begin{abstract}
This article develops the concept of proximity as socio-spatial distance by looking at the temporally and spatially condensed events of contemporary art exhibition openings. The article begins by examining some developments in proximity research, the limitations of theorizing the importance of proximity as mere physical nearness, arguing that potentiality renders proximity meaningful. After introducing the art event, we offer a three-pronged approach to proximity by showing the imperatives for being-there, the conditional indeterminacy of potentiality and the politics of proximity. In contrast to much recent research, it is argued that the significance of events is not reducible to evaluated outcomes. Two ethnographic vignettes show the imperatives, indeterminacies and politics in action. We conclude by showing how this conceptualization of proximity has analytic purchase beyond the empirical realm of contemporary art.
\end{abstract}

\section{Keywords}

art opening, Beijing, Berlin, contemporary art, events, potentiality, proximity, spatial theory

\section{Introduction}

Whether an art exhibition is on view for three days or three months, people in the art world are compelled to attend not only the exhibition but the opening event. This event - typically in the evening - inaugurates the exhibition and, despite its importance to the art worlds, remains relatively under-examined. The ritual of art openings brings social actors into specific locales in a condensed temporal moment, and this 
article draws out the significance of this confluence of location, temporality and social actors. These events in contemporary visual art worlds provide an empirical starting point to show the importance of potentiality in the concept of proximity. We argue that proximity becomes meaningful when social and physical nearness are brought together and facilitate potentialities.

The article begins with a brief review of literature dealing with proximity in clustering and field-configuring events, showing how a more rigorous concept calls for moving proximity beyond physical nearness. These perspectives can gain from a concept of proximity that more explicitly engages with the potentiality of socio-spatial situations, a move prefigured in the work of Simmel. This is contextualized within art world events and illustrated through the first of two ethnographic vignettes drawn from openings. The article then elaborates on the relationship between proximity and potentiality via a three-pronged approach. Firstly, we argue that the multiple imperatives to be co-present at art openings extend beyond the deterministic lens of social networking and careerism. Secondly, the physical proximity of social actors is rendered significant when proximity enables contingent potentialities to proliferate, including but not limited to those potentialities that are actualized. Another ethnographic vignette shows imperatives and potentialities in action, drawing us toward the politics of proximity. Thirdly, the potential for encounter, for future intimacies and uneven experiences shows how proximities can redistribute power. To conclude, we suggest how a concept of socio-spatial proximity facilitating potentialities can be used as a tool for analysis, and then show some of its conceptual compatibilities and broader implications.

\section{The Near and Far}

Recent empirical and concept-building research on proximity has been haunted by a focus on physical nearness. In part, this is due to the dynamics of meetings and travel that persist alongside of and despite telecommunications technologies (Urry, 2002), but it also relates to functional analysis of physical nearness spurring innovation, industrial development or sectoral growth. For instance, the importance of physical proximity has been a major topic for economic geographers interested in exploring 'innovation dynamics' (Agrawal et al., 2008; Balland et al., 2015). This literature suggests that the effects of clustering are not unilateral or static, acknowledging the difficulty in developing analytic tools to quantify or map exactly how proximity shapes, for instance, organizational innovation (see Benneworth and Henry, 2004; Porter, 1998).

Despite this function of co-presence, a basic concept of physical nearness is, in itself, relatively meaningless. For instance, Goffman recognizes that nearness is situationally conditioned: it might require 
non-acquaintances to learn civil inattentiveness as vital to the "rules for permissible engagement with strangers' sitting together on a train car (Goffman, 1971: 267), whereas in a village it might necessitate a personal greeting. The situation of strangers in a confined elevator (1971: 55-6) does not proliferate the same socio-spatial potentialities as those found at a trade fair populated by professionals (Lampel, 2011). Situations shape the meaningfulness of physical nearness. Collins (2004) shows that 'interaction rituals' need to begin with a focus on the situation, not the individual. Socio-spatial distance is rendered meaningful because of constellations of bodies and objects that become 'chained' together.

The concept of 'field-configuring events' has sought to tackle this problem by looking at the function of physical proximity in specific spatio-temporal events (Lange et al., 2014). Developed by scholars from diverse social scientific disciplines sharing interests in the so-called 'creative industries' (see Anand and Watson, 2004; Moeran and Pedersen, 2011) or organizational studies (Lampel and Meyer, 2008), this perspective describes the importance of temporary events in which diverse specialists and professionals gather together at a trade show, conference or other professional event to exchange ideas and products. They are the 'arenas in which networks are constructed, business cards are exchanged, reputations are advanced, deals are struck, news is shared, accomplishments are recognized, standards are set, and dominant designs are selected' (Lampel and Meyer, 2008: 1026). Instead of a fixed field, the goal is to take various snapshots of 'fields in flux' (Meyer et al., 2005) in which nonlinear change can be the result of these events. This perspective shows how co-presence enables new positions to be taken in a structured field while acknowledging that proximity is conditioned by the situation. We will argue below that while the focus on actualities and outcomes is empirically relevant and important, it nevertheless neglects to engage with potentialities of the situation.

Since Simmel, we possess tools to think of proximity as socio-spatial, imbued with diverse potentialities. He famously argues that indifference and the blasé attitude allow city dwellers to negotiate a gulf between physical closeness and social remoteness (Simmel, 1997). For Simmel, closeness and remoteness are always reciprocally conditioned - it makes no sense to speak of near unless far remains a possibility. Closeness and remoteness are always relational terms for Simmel, constituting what Cantó-Milà calls 'a leitmotif that weaves all his work together' that 'involve each other in a reality-creating (positive) way' (2016: 98). This 'positive' association is significant as an association 'out of which relationships, and subsequent forms of association, objects, practices and devices, may and do emerge' (Cantó-Milà, 2016: 85). Simmel gives multiple examples of associations in which near and far are reciprocal, from lovers, to roommates, to neighbours, to the stranger. There is no 'positive' relation possible with those speculative 'inhabitants of the star Sirius' who are beyond our reach 
because they lack this reciprocity: 'they stand outside of far and near' (Simmel, 2009: 601). Potentiality is only found in the far and the near. ${ }^{1}$ Taking the situational and the relational views in tandem, the significance of proximity begins to extend beyond physical nearness. It is situated in a particular time and place between certain actors. We explore this further through events and art openings.

\section{The Proliferation of the Event}

Unlike theories of the 'Event' writ large, marking moments of drastic historical change (Badiou, 2005, 2007; Sewell, 1996; Wagner-Pacifici, 2010, 2017; Žižek, 2014), the periodic, repetitive events of art openings are predominantly marked by an absence of societal or historic rupture. While everyday and periodic events are spatio-temporal, their temporality does not imply historicity.

In 1890, Simmel wrote what were likely his first critical reflections about the culture of urban modernity while inspired by an encounter with an art exhibition (Frisby, 2001: 102). Simmel's critical reflections of the 'multifarious' styles in this major exhibition, the 'blasé attitude' and the 'tireless desire to extract... the tiniest drop of originality' (Simmel, 2015: 89, 91) are core themes to which he returns again and again (Harrington, 2015). The writing that emerged in this context suggests that the art exhibition was still novel enough in his experience to force Simmel to stop, think and theorize.

Simmel was writing before theorists and historians entrenched the narrative of modern art as a series of successive movements. With the subsequent rejection of this grand narrative, art theorists have begun to define contemporary art as an interest in the immediate and the now, rather than a sense of linear progression (Osborne, 2013). Relyea argues that long-term political-aesthetic commitments are treated as archaic while exhibitions are epistemologically framed as events amidst a ceaselessly changing art world (Relyea, 2013: 18-20). Simmel's sense of agitation and excitement in 1890 feels incongruous with these changes, both with the epistemological framing of art in terms of the immediacy of events as well as the proliferation of these events. As visual art worlds and markets expand and events such as biennials, fairs and exhibitions at galleries and artist-run centres fill the annual calendar (Curioni, 2012; Thornton, 2008), the focus on immediacy becomes heightened through the eventization of art. Artists, curators, gallerists, critics and collectors are faced with more art exhibitions than they can possibly attend. Groys argues that artists, curators and museums are increasingly concerned with staging art in terms of events:

the production of art events is even more characteristic of contemporary art, with its culture of performance and participation ... Traditional 
art produced art objects. Contemporary art produces information about art events. (Groys, 2016: 4)

Or, in the words of Heinich (2000: 162), 'the world of art and literature is full of non-events as events'.

We focus on the exhibition opening as a condensed, shared moment of socio-spatial proximity, situated in an art world fixated with and configured by events. Our concept of proximity contributes to an explanation of why people continually participate in these events. The following ethnographic vignette presents the experiences of one opening event in Berlin. Providing a sense of the socio-spatial conditions and atmosphere of an art opening, the vignette will help illustrate and provide material for understanding the imperatives of being-there, the indeterminacy of potentiality and the politics of proximity.

\section{An Art Opening ${ }^{2}$}

It is an unseasonably warm evening in late April 2011 as Berlin hosts Gallery Weekend: an annual event where over forty galleries and art spaces simultaneously open new exhibitions. Inside Mathew Gallery are paintings, sculptures and drawings by three artists of different ages, reputations and market clout. Since its recent founding, openings at this gallery have become a popular destination for younger artists, but tonight's crowd is larger than normal despite the fact that there are forty coinciding, competing events at prestigious galleries. Rather than suits and high heels, this crowd of mostly twenty- and thirty-something artists, curators and their friends are casually dressed, hanging around on the street drinking beer and wine. Openings begin after the normal business hours of the gallery and offer the first opportunity for the public to view the exhibition. This event is peculiar insofar as the press release, sent out a week prior via email, informs us that the opening runs from 19:00 to 01:00, an unusually late event by typical gallery standards. A rumour is circulating of an unannounced musical performance: Kim Gordon, formerly of Sonic Youth, might perform in the small bar adjacent to the gallery. A performance was never advertised, but the rumour seems credible, as Gordon is one of the three exhibiting artists.

The gallery is compact and can comfortably contain about twenty bodies amidst these artworks before the crowd starts spilling out onto the sidewalk. Roughly two hundred people stand outside clustered near the gallery and bar. The size of the crowd suggests that this is an important event for younger members of the art world. A young man recently labelled as a top-ten 'young artist to watch' by an influential art blog is present, despite having his own artworks on view elsewhere at a major gallery across town. Apparently, he'd rather be here. 
New arrivals walking towards the gallery greet their friends with a double-cheek kiss. An artist I interviewed a few weeks ago arrives and plants kisses on twenty-four faces. She is introduced to people she doesn't know who also receive the greeting. Other rituals are occurring: beers and glasses of wine are drunk, jokes and stories are told and at least for a moment, most participants enter the gallery to look at art.

In the bar, Kim Gordon is making her way to the small stage elevated no more than one step above the rest of the room that can comfortably fit perhaps fifty bodies. While it is crowded, there is room for a few more. Moving out to the sidewalk, I notice something curious: though Gordon's rumoured performance was a primary attraction, most people are missing $i t$. The majority of the crowd appear oblivious. Voices begin to speak more loudly above the music to continue conversing, but otherwise the event outside the bar carries on as before. The value of being present at the gallery and Gordon's performance apparently finds its worth not merely in seeing art or hearing music. Being-there seems to be as or more important than actually experiencing the performance. This is where a selective group of artists with specialized knowledge are hanging out, friendships are being made and narratives written. The potentialities of being present here are myriad: being-there with others seems to hold special significance alongside the exhibition of objects and performance.

\section{Imperatives of Being-There}

This opening brought together hundreds of participants from Berlin's art world with knowledge that this would be the 'place to be' amongst the dozens of openings that night. Halle and Tiso describe 'two stories' of engagement with art: the art market and the art encounter (2014: 92), to which we would add a third: the event. The ritual of an exhibition opening is something social scientists are beginning to investigate as an important dynamic of contemporary art (Currid and Williams, 2010; Fuller, 2015; Jansson, 2014). This focus affirms the longstanding agreement that art worlds are necessary in order to create value for objects of cultural consumption (Becker, 1982; Danto, 1964) by considering the significance of social co-presence in physical locations and embodied networks (for examples, see Lowndes, 2010; Relyea, 2013; Stallabrass, 1999). The opening is a specific event, in which the social milieu (Currid, 2007), art scene (Lange, 2007) and evolution of 'buzz' (cf. Storper and Venables, 2004) come together in time and place. The 'buzz' around Kim Gordon's rumoured performance required 'a social milieu and thus close proximity', something Currid and Williams argue is vital to the 'valorization process' of art (2010: 6).

Though it may be convincing that the valorization system requires a social milieu, this does not clarify what is happening through compressed socio-spatial distance. To do this, we first argue that the significance of 
socio-spatial proximity is shaped by the imperatives of being-there. Film screenings, theatrical events or musical performances customarily involve an audience bound together for a duration of time, whereas visual art experiences do not always dictate the temporal frame of viewing. The social act of coming together in space and time is facilitated not simply by artworks but through opening events. These are the primary sites where a group of 'art lovers' come together as groups in physical nearness. As a select group of actors with something in common, namely a Bourdieusian belief in the value of art (Bourdieu, 1983), this is a constellation of actors with shared interests. As the primary sites of gatherings, the spatio-temporal event is shaped by two important more specific imperatives for attendance, underpinning the significance of proximity: 1) exclusivity of both the condensed time/space and limitations to attendance of the art opening, and 2) the event-based nature of contemporary art predicated on performance art and other forms of experiential art.

At a basic, pragmatic level, the opening offers an exclusive window of time to see artworks during the only hours that some people are capable of viewing the exhibition in person. Artists working day jobs or employees of art institutions are busy during normal operating hours, while opening events coincide with the end of their workday. In addition, many non-commercial art spaces and galleries do not have regular opening hours. For artist-run and project spaces, the event often reflects the limited resources of many art venues to keep regular opening times. In a comparative study of art spaces in Berlin and Beijing, the event often became the single way for artworks to be seen (Ren, 2016).

The opening is exclusive through various other tacit and explicit means. Forms of specialized knowledge are required to know when and where they occur. Knowledge of Kim Gordon's visit to Berlin was not available to all fans of Sonic Youth, but to those who had knowledge of the exhibition. Members of an art world have access to knowledge that eludes outsiders, tacitly marking 'openings' as something for 'us' - those within an art world. Visitors without specialized knowledge are in the minority, whether the event is at a blue chip gallery or an artist-run project space. In addition, unlike most gallery openings, the opening of an art fair or biennial is guarded by another echelon of exclusivity through invitations or tickets unavailable to the general public. Exclusivity does not purport that those who are co-present are one homogenous group, but that these 'barriers' of exclusivity already condition the situation encountered: those co-present can suppose a degree of social nearness merely by having arrived in physical nearness at a specific event. Standing on the sidewalk or in the bar next to Mathew Gallery implied some shared interests, acquaintances or knowledge and therefore a plateau of intimacy that was enabled by the socio-spatial situation. This proximity and the shared semi-intimate experience of an unadvertised performance evoked a sense of significance for those present. ${ }^{3}$ 
Another reason for social actors to gather at events is the increasing prevalence of performance, social and experiential modes of art that require being-there. Giesen claims that '[p]erformance art shifts the focus of artistic activity from the completion of an enduring piece ("the work") to the volatile event of a corporeal performance' that is temporally and spatially bound (Giesen, 2006: 315). Without the event, in other words, there is no art. Whereas a digital archive of the event is usually available, affect is strongest through physical, corporeal attendance. ${ }^{4}$ Still other artworks are only performed at the opening. Many large-scale art festivals, such as art fairs or biennials, include artworks commissioned specifically for the opening. For example, Minouk Lim's opening ceremony portion of the work Navigation ID in the 2014 Gwangju Biennale integrated the spectacle of busses, ambulances and a helicopter to bring to the festival site large metal containers filled with remnants of a massacre, which then remained on view for the duration of the biennial as a sculptural installation. Those who missed the opening could watch a video documentation of the transportation and involvement of grieving families at the opening, but the experience of being-there was singular.

The compressed spatio-temporalities, exclusivities and affect potentialities of performance art show that openings are more than valorization markets and sites of capital exchange. These imperatives contextualize and shape the ways that proximity becomes socio-spatially meaningful. But the possibility of meaningful encounters with art is one potentiality amidst many. The following section shows how events are rich in variable potentialities enabled by particular conditions.

\section{Proximity Enabling Potentiality}

The imperatives of being-there do not imply that the situation of an event is a homogenous experience. The spectacle of an iconic Kim Gordon performance was relatively absent for the majority of those present, while the experiences of hanging out with others who shared exclusive knowledge was a minor spectacle for some attendees. Proximity at events eludes an exclusively outcome-oriented view. At Mathew Gallery, a specific crowd were bound together in the socio-spatial event, but their experiences were differentiated, while the consequences of their attendance were indeterminate. To be clear, these indeterminacies are not completely unbounded. The indeterminacies are conditioned by the imperatives of being-there as exclusivities and milieu both enable and constrain the kinds of potential experiences that are possible, and for whom.

These conditioned situations facilitate the potentialities of proximity. When we speak of potentialities, we are referring to manifold possible futures rendered within the moment and situation. Tavory and Eliasoph 
(2013) suggest that these potentialities circulate in different temporalities of the future: from the immediate 'protentions' that anticipate the next moment and enable relatively smooth social action, to 'trajectories' of narratives and projects unfolding over time, to more taken-for-granted 'landscapes' of structured time. Greeting a new acquaintance with a kiss protends how the immediate future should proceed, while the opening event itself is part of the unfolding 'narrative' or 'project', structured within the periodicity of the eventized art world, of which Gallery Weekend is one event amongst many. Following Tavory and Eliasoph, the future orientation of potentialities are reciprocal: the near and far future are inter-related and a situation like an exhibition opening invites participants to engage with these possible futures.

Futures are rarely clear and structured, just as they are not exclusively struggled into existence. It is helpful here to think of artists as 'working with or playing with available resources' as 'experiments' (Human, 2014: 56) in the situation that includes but extends beyond a strategy or struggle for capital accumulation. Both possible and unrealized futures inhabit the concept of potentiality. Agamben argues that it is not the antithesis of actuality, but is saturated with the 'potential not to pass into actuality' (1999: 180). This is what we mean by indeterminacy. Mische describes both mundane and 'heroic' projections of the future, arguing that theorists need to attend to the 'open, indeterminate... point of view of the actor surveying the future in terms of multiple possibilities' rather than merely interpreting a 'decision after it has been taken' (2009: 696). Mische suggests that the contingent, possible and unrealized too quickly disappear from analysis. Potentialities are shaped by the situation and the actor(s), but these are not unilaterally reducible - by the outside researcher or actor - to actualities.

Potentialities circulate in heroic events as well as the mundane situations (cf. Featherstone, 1992) of another opening within an art world. Artists attending openings are faced with uncertain futures, in which the contingencies of the present situation circulate indeterminately, conditioned by the fact that their futures are intertwined with others in the art world, many of whom are also co-present. Physical nearness is significant because of the situation enabling potentiality. ${ }^{5}$ The formations of biographies rely on situated experiences of the present, images of a possible future and imaginaries that weave these images into a coherent narrative (Cantó-Milà and Seebach, 2015). For a single individual or group of artists, the Mathew Gallery opening could become a node within a narrative of a biography or career, including new intimacies, encounters or connections, but for the majority, this is one event unmarked by actualities.

Socio-spatial proximity at events enables the circulation of a conditioned indeterminacy that is meaningful. The result is not mere innovation, collaboration or field-configuration, but also the lingering of potentiality and possible futures never actualized. This helps us 
understand the recurring drive to attend events: there will always be that which has not actualized, an overflowing remainder of potentiality in the eventized art world. While artists may attend events in their struggles to accumulate symbolic, economic and cultural capital (Bourdieu, 1985), this is not always the case. One can attend the opening because of the multiple possibilities to view the art, gather with friends, drink free booze or have an alibi for arranging a meeting with a professional contact. Attending the opening does not necessarily imply one narration or one pursuit of potentialities, and this is what renders the opening particularly alluring.

The draw of indeterminacy provides a distinct enticement to come to the opening at Mathew Gallery, with exclusive knowledge compounded by the possibility of Kim Gordon's performance. Proximity was dually significant in the socio-spatial distance of being-there and through the potentialities that the event might have held, whether in the artworks or in proximity with other bodies and potential futures. The value of the experience was not functionally clear or transparent in actualities. Attendees arrived because of imperatives of being-there and the allure of indeterminacy, and they may or may not have left with any actualities. The researcher interested in quantifying actualities would be hard pressed to do so here, but proximity at Mathew Gallery was still rendered significant by the potentialities it facilitated.

A second ethnographic vignette shifts from the prior focus on one site, group and moment, to the interconnectedness of locales and persons over time, facilitated through the socio-spatial conditions of art opening events. Here we highlight again the imperatives of being-there and potentialities, while shifting towards the politics of proximity. This example shows more explicitly how capital exchanges and the formation of futures fall under but do not exhaust the politics of proximity.

\section{Another Art Opening}

'TJ in China' was an 'art space' in Beijing run by Mexican artists from Tijuana. Located in Caochangdi, an urban village outside of the fifth ring road in Beijing, TJ in China was not accessible by public transport and required some knowledge of Caochangdi to locate, as most taxis would not drive the narrow, unmarked streets. The exclusivity of events at this art space was therefore established through information and logistical accessibility. It was a space that pedestrians would not accidentally walk into, but a destination for those who knew how to get there.

Through events at TJ in China, the co-founders sought to fulfil their goal of fostering dialogue between artists and connecting with Chinese contemporary artists. Unable to speak Mandarin and coming from abroad to temporarily live in Beijing, these events offered a way for them to meet more local artists. Indeed, their individual and collaborative artistic 
practices were entwined with these events, not necessarily with the production of art works nor the materiality of the physical art space. One cofounder described, 'The space is [other co-founder] and me working on it. It's not the physical walls, you know?' (Personal Interview, 16 November 2012). The making of the art space was the primary purpose of being in Beijing, and they focused on this process of facilitating dialogue rather than the materiality of the space as characterizing their work.

During an art opening in November 2012, these aims became evident. Given the limited size of the art space, which only exhibited two artworks, people mostly congregated in the small entrance or sprawled into the courtyard. The co-founders organized to have a chua'r coal grill (skewered lamb) set up in the courtyard and people spent most of their time meeting and talking with the co-founders and other attendees. Beyond wanting to get to know more Chinese artists, there was no clear instrumental function evident in these events for other attendees. They were not offering residencies or commissions and did not have the resources to buy works or even offer exhibition possibilities. Rather, it was the potentiality that proximity evoked. Especially given the intimacy of a courtyard in an urban village in Beijing, the encounters of the attendees were rendered significant by their seclusion. The potential for a meaningful contact, for a possible future collaboration, for a means to gain insight into someone's artistic perspective or simply to enjoy an unexpected complimentary chua'r all rendered proximity more significant than just nearness.

Yet the unequal inter-subjective experience is also evidenced through the eventual benefits that materialized years later for the co-founders and the contacts they made through these art openings. The co-founders were invited back to Tijuana and awarded a government grant to run an art space, which would also feature Chinese artists. Based on their experience in Beijing, their networks and contacts, they stood to gain in material ways through these connections. Notably, even though there was no longer physical nearness, the meaningful encounters gained through these art openings enabled Chinese artists who met the co-founders to travel abroad, exhibit works and gain more visibility. But while in Beijing, none of these possibilities were directly evident. Through the conditions of exclusivity and access, the encounters at these events in an urban village in Beijing were rendered meaningful. This is not evidenced in the banality of eating chua'r and talking to people at the time of the art opening, but rather materialized later through an extended potentiality of future benefits.

\section{Towards a Politics of Proximity}

Introducing some of the politics of proximity, this brief story of $\mathrm{TJ}$ in China shows how certain spatial parameters of limited access to the gallery generated exclusivities, and it traces some of the retroactive actualities amidst the indeterminacies that brought people together in the first 
place. The indeterminacies of the art opening in Beijing were not infinite but conditioned through access to the gallery and encounters that actualized into transnational collaborations. Yet it is not the precise biographies, nor the exact outcomes, that rendered proximity meaningful. Rather, as the means through which potentialities were augmented, proximity was significant because of the multiple social potentialities of beingthere and conditioned indeterminacies. The potential of variable encounters draws artists to openings, pulling them back in for more, time and again.

Potentialities included the expectations and desires of attendance, the dynamic potential for the unexpected and the possibility to renegotiate a position within a relatively hierarchical art world. There is much to unpack in developing a politics of proximity, understanding politics in terms of its enabling qualities as 'power to' (potentia). In the case of TJ in China this included the possibilities that opened to the founders of the space when they returned to Tijuana. The material outcomes of the art opening were not equal for everyone present, but attendance was a necessary prerequisite for a possible invitation to Mexico. The politics of proximity highlight the nature of proximity as enabling, while also acknowledging it is not equally enabling for everyone. To explore this inequality, we will focus on the polythetic situation enabling future intimacies and the unequal possibilities generated through proximity that show the different scales of this concept.

At the interpersonal scale, art openings are conditioned situations in which social remoteness shrinks because attendees are part of a polythetic group. These events attract audiences that share overlapping characteristics: they are not all artists, not all of one age and have divergent interests within the arts. No single characteristic is universally shared amongst all, other than a relationship to art, but there is nevertheless a sufficient overlap of characteristics that bind them together.

By accessing exclusive events, attendees enter a situation with an inherent degree of limited intimacy because of the polythetic nature of the group. Physical nearness enhanced the potential for association and future deeper intimacies for a small group of attendees in the courtyard of an art space in an urban village on the outskirts of Beijing. At Mathew Gallery, huddled bodies in front of Kim Gordon, conversations on the street and kisses with new acquaintances show the potential for experiences and alliances that deepened the limited intimacies of attendees. The potential for future intimacies do not lie beyond the political. Art openings - with or without formal invitations - draw the art world to a situation that enhances the potentialities of future intimacies for a copresent group, brought together through knowledge and capacities for being-there. In other words, the exclusivity of the event both enhances the potentialities in the polythetic group while simultaneously excluding others. 
Similarly, socio-spatial proximity does not infer that those co-present stand on equal footing. Unequal possibilities or gains in experience are of course based on differentials between social actors, as some stand to gain more through their attendance than others, based on a variety of factors in terms of resource endowments, recognizability, etc. Differential experiences are always occurring and part of the potentiality of the event. Not every subjectivity engages with the same notion of the event: McRobbie's research on cultural economy labour markets shows that the same situation can be interpreted as a celebratory moment of pleasure or as an instrumentalized disciplinary technique of the creative economy, or both simultaneously $(2004,2015)$. For both researchers and social actors, it is easier to recognize the winners of the politics of proximity than those who do not gain desired actualities, or who may be excluded from the opening completely. This partially explains why proximity research so often insists on actualities, or why the theory of the 'creative class' celebrates the most successful (as in Currid, 2007), while invisible currents of never-actualized potentialities tend to be narrated in retrospect by those with insider knowledge (as in Sholette, 2010).

Finally, the politics of proximity are relevant beyond the scale of the inter-subjective. Some art events are designed to bring certain places closer to the heartlands of the global art world. A concept of socio-spatial proximity that articulates imperatives of being-there, potentialities and the political is useful for the analysis of the biennial as a spectacle or tool for urban redevelopment (Quinn, 2005). For instance, when an art biennial is established in Kampala, it is not merely aiming to bring Kampalan or Ugandan artists together, but to bring the international art world to Kampala. This is achieved through an event of 'international' artists and artists from the region, attracting members of the international art world to the city. The significance of proximity as both social and physical nearness is great because of desired actualities and potential gains achieved through attendance and recognition of Kampala's importance on a global scale. There are new potentialities for artists, curators, institutions and the city itself to gain in multiple economic, social and symbolic ways on various scales. In contrast, the city of Venice does not stand to gain from the potentialities of proximity to the same relative extent. The first and most famous art biennial is imbued with potentiality for those in attendance, but the stakes are relatively small for a city that is well established on a global stage of urban entrepreneurialism (Harvey, 1989). The distribution and stakes of potentialities are unequal, between subjects as well as the events themselves.

\section{Conclusion}

The art opening event is a useful lens to understand how conditioned situations cast physical and social nearness as socio-spatial proximity. It 
is this confluence of factors that facilitates the circulation of potentialities meaningful to those present. In addition, we have argued that proximity needs to be understood beyond the actualities it facilitates. Without negating the importance of actualities, this article has sought to show that potentiality is both an explanation for how an eventized art world holds allure even without actualities and that actualities do not exhaust the meaningfulness of socio-spatial proximity.

The eventized art world is a stage for the performance of symbolic value and markets of capital exchange, but we seek to go beyond the market and the stage. The two openings show the processual nature of a world of events - where physical nearness is part of a social ritual of gathering. In positing that the significance of proximity lies in its facilitation of potentiality, we contend that its significance is in its dynamism and not in its determinism. We have pointed towards the significance of proximity as socio-spatial distance that replaces an essentialist 'Heideggerian ontology of being-in-the-world with a more Deleuzian notion of becoming-in-the-world' (Dovey, 2009: 6).

The conditioned indeterminacies of the opening and the potentialities for future intimacies within the situation provide tools to think about dynamic and political everyday events. This concept of proximity may serve simultaneously as an analytical instrument as well as a tactic of subjectivity. In analysing art openings, it helps us understand the compulsion of being-there in the compressed time and space of the opening, even though the exhibition is on view for days, weeks or months and is circulated via image and text in the online archive. The spatio-temporality of the event offers intensities and bodily experiences that the exhibition and the archive do not. As a tactic of subjectivity, proximity enables those present to renegotiate their positions - whether an individual's or a group's station in an art world, their possible futures together and apart, or in the collective efforts to redraft the map of the art world itself. Given the claims in a diversity of disciplines from art criticism to urban studies about the need to de-centre or expand the fixed parochial points of reference (Roy, 2009), proximity can serve as a means to think about space, events and actors in this process of becoming.

This concept of proximity can also travel. Despite originating from empirical research set in contemporary art, socio-spatial proximity distinguished by its potentialities carries relevance into other fields, from individuals, groups or cities negotiating events in specific spatio-temporalities or in the role of proximity in events where history appears to rupture. The multiplicities of potentiality help us better understand individual or collective orientations to the present and future that include but are not reducible to the strategic or the actual. It has broad relevance in the social and political sciences where critical research attends to the actual as well as the possible. 
Through proximity we encourage interpretations of findings that take seriously subjectivities and tactics by developing a concept with analytic purchase. This enables researchers to uncover and understand the conditions under which socio-spatial distance facilitates potentiality. To ignore potentiality is to risk losing sight of how events, both heroic and mundane, bind together and hold apart. This perspective allows for a more holistic research design, in which needed attention is drawn to findings that might escape measurement under the economic fixations of cross-fertilization, field configuration or innovation discourses. Attending to the confluence of a specific conditioned, spatio-temporal situation that facilitates potentialities allows us a deeper understanding of the near and far. In short, this is a concept of proximity that renders distance meaningful.

\section{Notes}

1. Simmel's use of Nähe und Distanz (or occasionally, Ferne) is usually translated as proximity and distance. Our use of these terms differs slightly. Near and far are relational poles of a dynamic spectrum, whereas the term distance is more general: distance can be far or near.

2. The two vignettes invoke different ethnographic styles of writing. The first utilizes in situ first-person descriptive narration while the second narrates on the basis of interviews and observation from outside the action. These styles achieve unique purposes for the article - the first as a description that sets the stage for the analysis sections on imperatives of being-there and proximity enabling potentiality, while the second draws upon this analysis and shows the necessity of a politics of proximity.

3. Social nearness here does not imply friendliness, but refers to the forming of a relational situation and group. Following Simmel, the nearness and remoteness of co-presence takes on a situated significance that leads to the emergence of new forms of social remoteness and nearness. For instance, outside the art world, a famous collector and unknown artist appear to share nearness through their common interest in art, while at an opening, it might be remoteness that best describes their association.

4. The popularization of ephemeral, site-specific performative works is evidenced in the artist Tino Sehgal's performance piece, 'this variation', at documenta 13 in which the audience must experience the work in person because there is almost nothing to see. Described by Sehgal as a 'constructed situation', the work takes place in a darkened room with moments of flashing light and is comprised of a group of performers' movements and sounds through which the audience wanders. Performers whose eyes have adapted to the dark can move around newcomers, chanting and provoking an uncanny experience of being in the middle of a performance that one cannot see or visually record. Neither film nor video can catalogue the sensory experience of attempting to move in a space without light, slowly adapting one's vision to darkness and being surrounded by performers. The audience must be present in order to witness the art. Invisible yet audible 
proximity to the performers and other viewers unsettles one's expectations of performance, refiguring the notion of stage to pure co-presence.

5. This is most clear from the interpretive vantage point of the researcher, while artists often possess tacit yet precise knowledge about these dynamics (see Fuller, 2015: 125).

\section{References}

Agamben, Giorgio (1999) Potentialities: Collected Essays in Philosophy. Stanford: Stanford University Press.

Agrawal, Ajay, Kapur, Devesh and McHale, John (2008) How do spatial and social proximity influence knowledge flows? Evidence from patent data. Journal of Urban Economics 64(2): 258-269.

Anand, Narasimhan and Watson, Mary R. (2004) Tournament rituals in the evolution of fields: The case of the Grammy Awards. The Academy of Management Journal 47(1): 59-80.

Badiou, Alain (2005) Handbook of Inaesthetics. Stanford: Stanford University Press.

Badiou, Alain (2007) Being and Event. London: Continuum.

Balland, Pierre-Alexandre, Boschma, Ron and Frenken, Koen (2015) Proximity and innovation: From statics to dynamics. Regional Studies 49(6): 907-920.

Becker, Howard (1982) Art Worlds. Berkeley: University of California Press.

Benneworth, Paul and Henry, Nick (2004) Where is the value added in the cluster approach? Hermeneutic theorising, economic geography and clusters as a multiperspectival approach. Urban Studies 41(5-6): 1011-1023.

Bourdieu, Pierre (1983) The field of cultural production, or: The economic world reversed. Poetics 12(4): 311-356.

Bourdieu, Pierre (1985) The market of symbolic goods. Poetics 14(1): 13-44.

Cantó-Milà, Natàlia (2016) On the special relation between proximity and distance in Simmel's forms of association and beyond. In: Kemple, Thomas and Pyyhtinen, Olli (eds) The Anthem Companion to Georg Simmel. London: Anthem Press, pp. 81-100.

Cantó-Milà, Natàlia and Seebach, Swen (2015) Desired images, regulating figures, constructed imaginaries: The future as an apriority for society to be possible. Current Sociology 63(2): 198-215.

Collins, Randall (2004) Interaction Ritual Chains. Princeton: Princeton University Press.

Curioni, Stefano Baia (2012) The art system, globalization, and the fair movement. In: Curioni, Stefano Baia and Van den Berg, Karen eds) Contemporary Art and its Commercial Markets: A Report on Current Conditions and Future Scenarios. Berlin: Sternberg Press, pp. 115-152.

Currid, Elizabeth (2007) The Warhol Economy. Princeton: Princeton University Press.

Currid, Elizabeth and Williams, Sarah (2010) The geography of buzz: Art, culture and the social milieu in Los Angeles and New York. Journal of Economic Geography 10(3): 423-451.

Danto, Arthur (1964) The artworld. The Journal of Philosophy 16(19): 571-584.

Dovey, Kim (2009) Becoming Places: Urbanism / Architecture / Identity / Power. Abingdon: Routledge. 
Featherstone, Mike (1992) The heroic life and everyday life. Theory, Culture \& Society 9(1): 159-182.

Frisby, David (2001) Cityscapes of Modernity. Cambridge: Polity.

Fuller, Martin (2015) Less than friends, more than acquaintances: Artists, markets and gallery openings in New York. International Review of Social Research 5(2): 120-129.

Giesen, Bernhard (2006) Performance art. In: Alexander, Jeffrey C., Giesen, Bernhard and Mast, Jason L. (eds) Social Performance: Symbolic Action, Cultural Pragmatics, and Ritual. Cambridge: Cambridge University Press, pp. 315-323.

Goffman, Erving (1971) Relations in Public: Microstudies of the Public Order. Middlesex: Penguin.

Groys, Boris (2016) In the Flow. London: Verso.

Halle, David and Tiso, Elisabeth (2014) New York's New Edge: Contemporary Art, the High Line, and Urban Megaprojects on the Far West Side. Chicago: University of Chicago Press.

Harrington, Austin (2015) Introduction to Georg Simmel's essay 'On Art Exhibitions'. Theory, Culture \& Society 32(1): 83-85.

Harvey, David (1989) From managerialism to entrepreneurialism: The transformation in urban governance in late capitalism. Geografiska Annaler. Series B, Human Geography 71(1): 3-17.

Heinich, Nathalie (2000) What is an artistic event? Boekmancahier 12(44): 159-168.

Human, Oliver (2014) Potential novelty: Towards an understanding of novelty without an event. Theory, Culture \& Society 32(4): 45-63.

Jansson, Johan (2014) Temporary events and spaces in the Swedish art market. Zeitschrift für Wirtschaftsgeographie 58(4): 202-215.

Lampel, Joseph (2011) Afterword: Converting values into other values: Fairs and festivals as resource valuation and trading events. In: Moeran, Brian and Pedersen, Jesper Strandgaard (eds) Negotiating Values in the Creative Industries: Fairs, Festivals and Competitive Events. Cambridge: Cambridge University Press, pp. 334-347.

Lampel, Joseph and Meyer, Alan D. (2008) Guest editors' introduction. Journal of Management Studies 45(6): 1025-1035.

Lange, Bastian (2007) Die Räume der Kreativszenen Culturepreneurs und ihre Orte in Berlin. Bielefeld: Transcript.

Lange, Bastian, Power, Dominic and Suwala, Lech (2014) Geographies of fieldconfiguring events. Zeitschrift für Wirtschaftsgeographie 58(4): 187-201.

Lowndes, Sarah (2010) Social Sculpture: The Rise of the Glasgow Art Scene. Edinburgh: Luath Press Ltd.

McRobbie, Angela (2004) Making a living in London's small-scale creative sector. In: Power, D. and Scott, A.J. (eds) Cultural Industries and the Production of Culture. Oxford: Routledge.

McRobbie, Angela (2015) Be Creative: Making a Living in the New Culture Industries. Cambridge: Polity Press.

Meyer, Alan D., Gaba, Vibha and Colwell, Kenneth A. (2005) Organizing far from equilibrium: Nonlinear change in organizational fields. Organization Science 16(5): 456-473.

Mische, Ann (2009) Projects and possibilities: Researching futures in action. Sociological Forum 24(3): 694-704. 
Moeran, Brian and Pedersen, Jesper Strandgaard (eds) (2011) Negotiating Values in the Creative Industries: Fairs, Festivals and Competitive Events. Cambridge: Cambridge University Press.

Osborne, Peter (2013) Anywhere or Not at All. London: Verso.

Porter, Michael E. (1998) Clusters and new economics of competition. Harvard Business Review 76: 77-90.

Quinn, Bernadette (2005) Arts festivals and the city. Urban Studies 42(5-6): 927943.

Relyea, Lane (2013) Your Everyday Art World. Cambridge, MA: MIT Press.

Ren, Julie (2016) 'Creative class' subversions: Art spaces in Berlin and Beijing. In: Wang. J. and Yang, Y. (eds) Making Cultural Cities in Asia: Mobility, Assemblage, and the Politics of Aspirational Urbanism. Abingdon: Routledge, pp. 177-190.

Roy, Ananya (2009) The 21st-century metropolis: New geographies of theory. Regional Studies 43(6): 819-830.

Sewell, William H. (1996) Historical events as transformations of structures: Inventing revolution at the Bastille. Theory and Society 25(6): 841-881.

Sholette, Gregory (2010) Dark Matter: Art and Politics in the Age of Enterprise. London: Pluto Press.

Simmel, Georg (1997) The metropolis and mental life. In: Frisby, D. and Featherstone, M. (eds) Simmel on Culture. London: SAGE, pp. 174-185.

Simmel, Georg (2009) Sociology: Inquiries into the Construction of Social Forms. Leiden: Brill.

Simmel, Georg (2015) On art exhibitions. Theory, Culture \& Society 32(1): 8792.

Stallabrass, Julian (1999) High Art Lite: British Art in the 1990s. London: Verso.

Storper, Michael and Venables, Anthony J. (2004) Buzz: Face-to-face contact and the urban economy. Journal of Economic Geography 4(4): 351-370.

Tavory, Iddo and Eliasoph, Nina (2013) Coordinating futures: Toward a theory of anticipation. American Journal of Sociology 118(4): 908-942.

Thornton, Sarah (2008) Seven Days in the Art World. New York: WW Norton.

Urry, John (2002) Mobility and proximity. Sociology 36(2): 255-274.

Wagner-Pacifici, Robin (2010) Theorizing the restlessness of events. American Journal of Sociology 115(5): 1351-1386.

Wagner-Pacifici, Robin (2017) What Is an Event? Chicago: University of Chicago Press.

Žižek, Slavoj (2014) Event: Philosophy in Transit. London: Penguin.

Martin Fuller is a researcher in the Department of Sociology at the Technische Universität Berlin.

Julie Ren is research faculty at the Geography Department, HumboldtUniversität zu Berlin. 